\title{
Post-training intrahippocampal injection of synthetic poly- $\alpha-2,8$-sialic acid-neural cell adhesion molecule mimetic peptide improves spatial long-term performance in mice
}

\author{
Cédrick Florian, ${ }^{1}$ Jane Foltz, ${ }^{1}$ Jean-Chrétien Norreel, ${ }^{2}$ Geneviève Rougon, ${ }^{2}$ and \\ Pascal Roullet ${ }^{1,3}$ \\ ${ }^{1}$ Centre de Recherches sur la Cognition Animale, CNRS 5169, Université Paul Sabatier, 31062 Toulouse, France; ${ }^{2}$ Institut de \\ Biologie du Développement de Marseille-Luminy, CNRS 6216 Université de la Méditerranée, 13288 Marseille, France
}

\begin{abstract}
Several data have shown that the neural cell adhesion molecule (NCAM) is necessary for long-term memory formation and might play a role in the structural reorganization of synapses. The NCAM, encoded by a single gene, is represented by several isoforms that differ with regard to their content of $\alpha$-2,8-linked sialic acid residues (PSA) on their extracellular domain. The carbohydrate PSA is known to promote plasticity, and PSA-NCAM isoforms remain expressed in the CA3 region of the adult hippocampus. In the present study, we investigated the effect on spatial memory consolidation of a PSA gain of function by injecting a PSA mimetic peptide (termed pr2) into the dorsal hippocampus. Mice were subjected to massed training in the spatial version of the water maze. Five hours after the last training session, experimental mice received an injection of pr2, whereas control mice received PBS or reverse peptide injections in the hippocampal CA3 region. Memory retention was tested at different time intervals: $24 \mathrm{~h}, 1$ wk, and 4 wk. The results showed that the post-training infusion of pr2 peptide significantly increases spatial performance whenever it was assessed after the training phase. By contrast, administration of the control reverse peptide did not affect retention performance. These findings provide evidence that (1) PSA-NCAM is involved in memory consolidation processes in the CA3 hippocampal region, and (2) PSA mimetic peptides can facilitate the formation of long-term spatial memory when injected during the memory consolidation phase.
\end{abstract}

Evidence has been found to suggest that the properties of the memory trace change in a time-dependent manner. The formation of a long-term memory involves the conversion of a labile short-term memory into a long-lasting stable trace (Muller and Pilzecker 1900; McGaugh 2000; Dudai 2004). This process of post-acquisition stabilization of the trace within minutes or hours after the learning is called memory consolidation or, more precisely, cellular or synaptic consolidation (Dudai and Morris 2000). Synaptic consolidation has been described in numerous species and in various long-term memory tasks (see Dudai 2004). Moreover, in function of the type of memories tested, consolidation involves distinct brain regions (Ambrogi Lorenzini et al. 1999). Nevertheless, consolidation of many types of memories and especially of spatial memory depends on hippocampal processing, and memory consolidation correlates with changes in neuronal connectivity pattern in this structure (Andersen and Soleng 1998; Bailey et al. 2000; Martin et al. 2000). This synaptic reorganization depends on the activation of molecular cascades, and considerable evidence suggests that the neural cell-adhesion molecules (NCAMs) are crucial players in these events (Bailey et al. 1992, Doyle et al. 1992a; Ronn et al. 1995). Two waves of NCAM synthesis are observed, one immediately following training and a second several hours (4-8 h) post-training (Doyle et al. 1992a; Rose, 1995a,b). This second wave of glycoprotein synthe-

\section{${ }^{3}$ Corresponding author.}

E-mail roullet@cict.fr; fax 33-05-61-55-61-54.

Article published online before print. Article and publication date are at http:// www.learnmem.org/cgi/doi/10.1101/lm.187506. sis seems to be essential for long-term memory formation. Intraventricular injections of anti-NCAM antibodies $6-8 \mathrm{~h}$ following passive avoidance training or anti-L1-injected $5.5 \mathrm{~h}$ after a visual categorization task impair retention performance in chicks (Scholey et al. 1993; Tiunova et al. 1998). Similar results were found in the rat after injections of anti-NCAM 5-6 h after different learning tests (Doyle et al. 1992a; Arami et al. 1996; Alexinsky et al. 1997; Roullet et al. 1997).

We aimed here to evaluate the effects of specific NCAM isoforms, the polysialylated neural NCAM (PSA-NCAM). The post-transcriptional addition of long chains of polysialic acid (PSA) to NCAM, the only identified protein carrier of this carbohydrate, modifies the relative degree of overall membranemembrane apposition between cells, a mechanism that is involved in neural plasticity (Rougon 1993; Seki and Arai 1993). We investigated the role of the hippocampal PSA-NCAM during the synaptic consolidation of spatial learning, focusing on the CA3 subregion of the hippocampus. First, in previous studies, we observed impairment of the long-term memory performance following total inactivation of the dorsal CA3 subfields in different spatial learning tasks (Stupien et al. 2003; Florian and Roullet 2004). Second, PSA immunoreactivity was observed in the CA3 subfield, which represents the mossy fiber termination field on the apical dendrites of pyramidal neurons (see, for example, Eckhardt et al. 2000). Third, PSA-NCAM seems to be involved in memory formation since an increase of the PSA-NCAM level is observed in the dentate gyrus of the hippocampus $10-12 \mathrm{~h}$ following training in spatial or conditioned avoidance tasks (Doyle et al. 1992b; Fox et al. 1995; O'Connell et al. 1997; Sandi et al. 

effects induced by a down-regulation of either total NCAM or PSA expression via the use of genetically modified mice (Cremer et al. 1994; Eckhardt et al. 2000) or endo-neuraminidase treatment, which specifically removes PSA (Becker et al. 1996; Muller et al. 1996). We used a new and complementary approach that consisted of mimicking the PSA action in this region. To this end, we used the synthetic PSA mimetic cyclic peptide CSLIASMETGCG with a disulfide bridge linking cysteines 1 and 11 (hereafter termed pr2), synthesized and characterized by Torregrossa and collaborators (2004). In brief, this peptide showed in vitro and in vivo bioactivity, promoting axonal growth, defasciculation, and migration of grafted neural progenitors consistent with a PSA mimicking effect. Hence, to investigate the effect of mimicking PSA in memory processes, we used the Morris water maze (MWM) with a new behavioral massed-procedure, allowing all training sessions to be performed within a short period of time (maximum duration, $80 \mathrm{~min}$ ). Pr2 was injected $5 \mathrm{~h}$ after the last training session, i.e., during the second wave of glycoprotein synthesis mentioned above. In agreement with the notion that the CA3 region seems to be crucial for the treatment of information necessary for the long-term memory formation and exhibits changes in neuronal connectivity pattern during consolidation, we observed that pr2 facilitates memory consolidation and increases recall performance.

\section{Results}

\section{Massed-learning trials acquisition in the spatial version} of the MWM

Before being injected, three mouse groups (phosphate buffer saline [PBS], $n=29$; reverse, $n=30 ; \mathrm{pr}, n=28$ ) were subjected to four learning sessions. For the mean latencies before escape onto the hidden platform, a repeated-measure ANOVA of the entire data revealed a significant session effect $\left(F_{(3,252)}=5.319\right.$, $P<0.001)$ but no pre-treatment effect $\left(F_{(2,84)}=0.237, P=0.789\right)$ and no interaction between these two factors $\left(F_{(6,252)}=0.101\right.$, $P=0.996)$. These data confirmed that before treatment the three groups of mice learned the exact position of the platform and reached the same level of performance during the four learning sessions.

After the training phase, mice from each group were subjected to the 60 -sec probe test trial either $24 \mathrm{~h}$ (PBS, $n=9$; reverse, $n=10 ; \operatorname{pr} 2, n=8), 1 \mathrm{wk}$ (PBS, $n=12$; reverse, $n=12 ; \operatorname{pr} 2, n=12$ ), or 4 wk (PBS, $n=8$; reverse, $n=8$; pr2, $n=8$ ) post-training. The nine subgroups are independent; i.e., each mouse is only tested once for a given retention interval and a given treatment. Treatment consisted of the injection in the CA3 region of $0.25 \mu \mathrm{L}$ of solution of either peptide pr2 or its reverse counterpart or $0.25 \mu \mathrm{L}$ of PBS. Reverse peptide and PBS conditions were used as controls.

\section{Effect of PSA mimetic peptide infusion on 24-h spatial retention test}

As shown in Figure 1, A and B, infusion of pr2 $5 \mathrm{~h}$ after training enhances long-term retention during the probe test performed $24 \mathrm{~h}$ later. A two-way ANOVA revealed no significant effect in the time spent in the four quadrants between PBS-, reverse-, and pr2-injected mice $\left(F_{(2,96)}=0.000, P=1\right)$, but a significant quadrant effect $\left(F_{(3,96)}=204.893, P<0.001\right)$ and especially a significant treatment $\times$ quadrant interaction $\left(F_{(6,96)}=10.156\right.$, $P<0.001)$. Post hoc analysis showed that for each treatment (PBS, reverse, and pr2), animals spend more time in the target quadrant than in the three others $(P s<0.001)$. Moreover, mice that received hippocampal infusion of pr2 stay longer in the

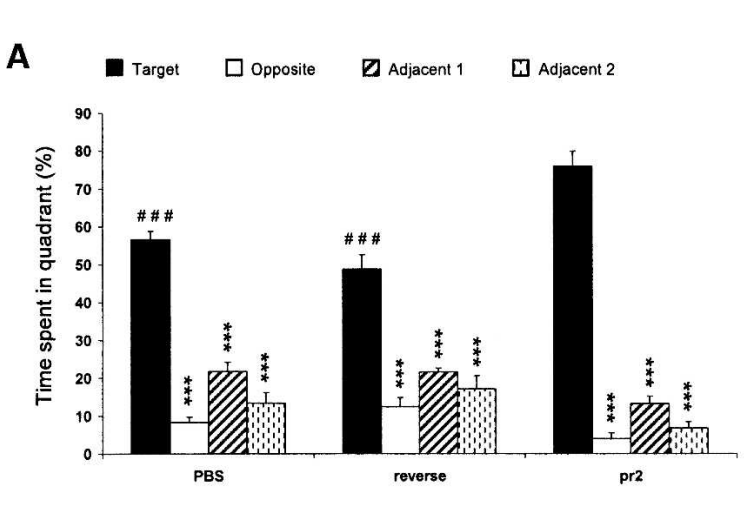

B

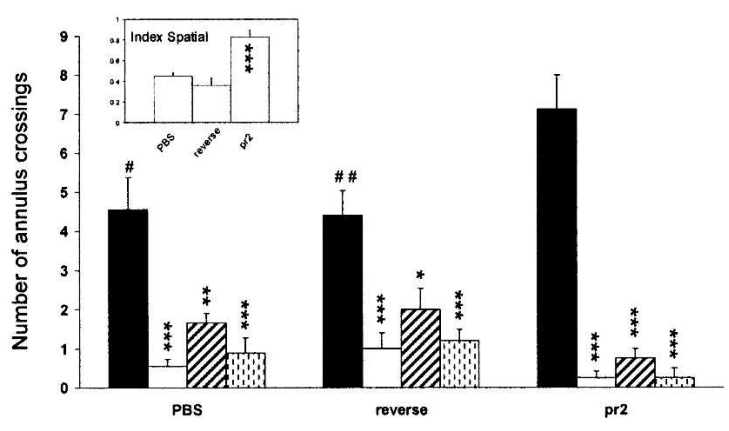

Figure 1. Spatial retention test $24 \mathrm{~h}$ after the massed learning sessions. (A) Percentage of time spent swimming in the four quadrants by PBS-, reverse-, and pr2-injected mice. (B) Mean of annulus crossings during the probe test. The inset displays the index score of mice during the retention test. ${ }^{* * *} P<0.001,{ }^{* *} P<0.01,{ }^{*} P<0.05$ compared with target quadrant. $\# \# \#<0.001, \# \# P<0.01,{ }^{\#} P<0.05$ compared with the target quadrant of the pr2 group. The comparison pr2 vs. PBS and reverse is shown in the inset.

target quadrant $(\sim 76 \%$ of time) than either PBS- and reverseinjected mice (Ps $<0.001)$.

Moreover, a two-way ANOVA revealed no significant effect among PBS-, reverse-, and pr2-injected mice $\left(F_{(2,96)}=0.263\right.$, $P=0.77$ ) on the number of annulus crossings (Fig. 1B), but a significant quadrant effect $\left(F_{(3,96)}=64.047, P<0.001\right)$ and a significant treatment $\times$ quadrant interaction $\left(F_{(6,96)}=4.184\right.$, $P<0.001)$. Tukey's test showed that control mice significantly crossed the target annulus several times more than the opposite and adjacent two annuli $(P s<0.001)$ and more than the adjacent one (PBS, $P<0.01$; reverse, $P<0.05$ ). Pr2-treated mice crossed the target annulus more often than the three other annuli $(P s<0.001)$ and the target quadrant more often than the two control groups (PBS, $P<0.05$; reverse, $P<0.01$ ).

One-way ANOVA revealed a significant treatment effect $\left(F_{(2,24)}=17.787, P<0.001\right)$ and post hoc test a better memory index score for the pr2-injected mice than that of the two control groups $(P s<0.001)$.

\section{Effect of PSA mimetic peptide infusion on 1 wk spatial retention test}

Figure $2 \mathrm{~A}$ shows the time spent in quadrant when the probe test is performed $1 \mathrm{wk}$ after the training phase. ANOVA revealed no treatment effect $\left(F_{(2,132)}=0.000, P=1\right)$, a significant quadrant 
A

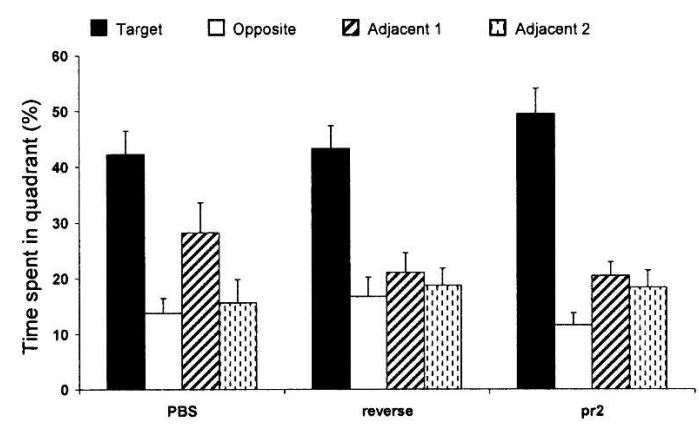

B

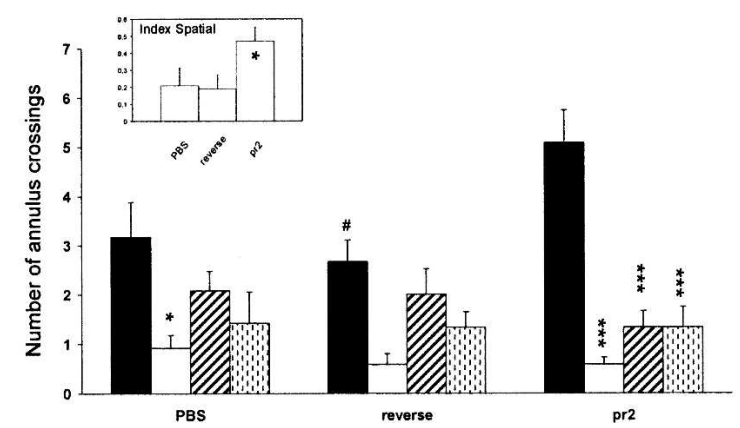

Figure 2. Spatial retention test $1 \mathrm{wk}$ after the massed learning sessions. (A) Percentage of time spent swimming in the four quadrants by PBS-, reverse-, and pr2-injected mice. (B) Mean of annulus crossings during the probe test. The inset displays the index score of mice during the retention test. ${ }^{* *} P<0.001,{ }^{*} P<0.05$ compared with target quadrant. ${ }^{\#} P<0.05$ compared with the target quadrant of the pr2 group. The comparison pr2 vs. PBS and reverse is shown in the inset.

effect $\left(F_{(3,132)}=42.434, P<0.001\right)$, and no significant interaction between these two factors $\left(F_{(6,132)}=1.070, P=0.384\right)$.

A two-way ANOVA revealed that there was no significant effect among PBS-, reverse-, and pr2-injected mice $\left(F_{(2,132)}=0.914, P=0.403\right)$ on the number of annulus crossings (Fig. 2B), a significant quadrant effect $\left(F_{(3,132)}=22.652\right.$, $P<0.001)$, and a treatment $\times$ quadrant interaction $\left(F_{(6,132)}=2.599, P=0.021\right)$. Post hoc analysis showed that pr2injected mice presented a clear preference for the target quadrant compared with the three other quadrants $(P<0.001)$. Moreover, these pr2 mice crossed the target annulus several times more often than the two control groups, although a significance is only found with the reverse group $(P<0.05)$. In the PBS group, the target quadrant is more widely explored, but only in comparison with the opposite quadrant $(P<0.05)$, and for the reverse group, there is no significant difference in the exploration of the four quadrants.

For the index score, a significant treatment effect has been found $\left(F_{(2,33)}=4.238, P=0.023\right)$ (Fig. $\left.2 \mathrm{~B}\right)$ and post hoc test revealed a difference between pr2-injected mice and the two control groups (Ps<0.05).

\section{Effect of PSA peptide infusion on 4-wk spatial retention test}

Figure $3 \mathrm{~A}$ shows the time spent in quadrants when the probe test is performed $4 \mathrm{wk}$ after the training phase. A two-way analysis revealed no significant effect on the percentage of time spent in the four quadrants among PBS-, reverse-, and pr2-injected mice $\left(F_{(2,84)}=0.000, P=1\right)$, a significant quadrant effect $\left(F_{(3,84)}=40.735, P<0.001\right)$, and a significant treatment $\times$ quadrant interaction $\left(F_{(6,84)}=3.483, P<0.01\right)$. Post hoc analysis showed that mice injected with the peptide pr2 explored the target quadrant more actively than in the three other quadrants (target vs. opposite/adjacent $2, P<0.001$; target vs. adjacent 1 , $P<0.01)$. In the control groups, the target quadrant is also more widely explored but only in comparison with some other quadrants (PBS: target vs. adjacent $1, P<0.05$; target vs. opposite, $P<0.001$; reverse: target vs. adjacent $2, P<0.05$; target vs. opposite $P<0.001)$. Moreover, post hoc analysis showed that pr2injected mice did not swim significantly more in the target quadrant than the two control groups.

Figure $3 \mathrm{~B}$ shows the number of annulus crossings during the probe test. A two-way ANOVA revealed no significant effect among PBS-, reverse-, and pr2-injected mice $\left(F_{(2,84)}=0.961\right.$, $P=0.387)$, a significant quadrant effect $\left(F_{(3,84)}=9.554\right.$, $P<0.001)$, and a treatment $\times$ quadrant interaction $\left(F_{(6,84)}=3.221, P<0.01\right)$. The control animals did not cross the target annulus more times than the others, suggesting that these animals had forgotten the platform location. In contrast, pr2injected mice crossed the target annulus more times (target vs. opposite, $P<0.001$; target vs. adjacent $2, P<0.05$ ). Moreover,

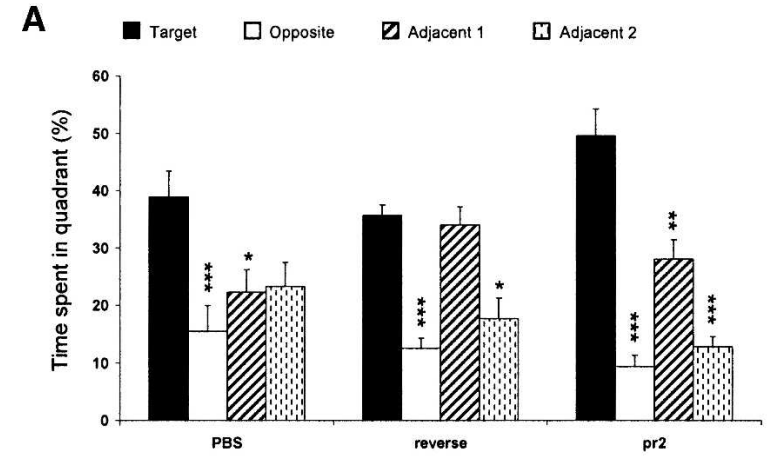

B

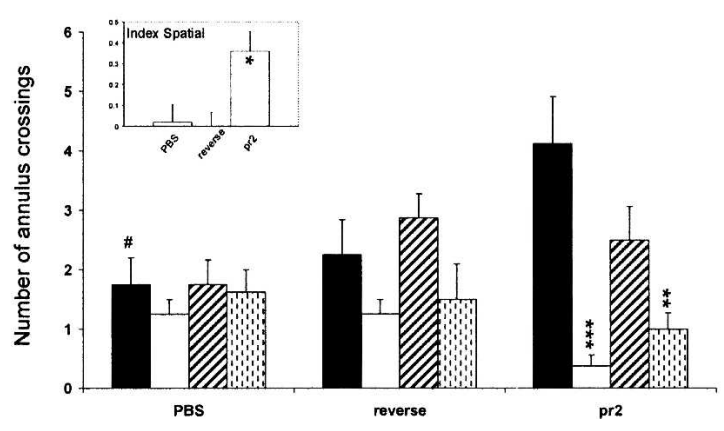

Figure 3. Spatial retention test $4 \mathrm{wk}$ after the massed learning sessions. (A) Percentage of time spent swimming in the four quadrants by PBSreverse-, and pr2-injected mice. (B) Mean of annulus crossings during the probe test. The inset displays the index score of mice during the retention test. ${ }^{* * *} P<0.001,{ }^{* *} P<0.01,{ }^{*} P<0.05$ compared with target quadrant. ${ }^{\#} P<0.05$ compared with the target quadrant of the pr2 group. The comparison pr2 vs. PBS and reverse is shown in the inset. 
pr2-injected mice crossed the target annulus more times than the two control groups, but this is only significant with the PBS group $(P<0.05)$.

ANOVA performed on the index score revealed a significant treatment effect $\left(F_{(2,21)}=5.841, P<0.01\right)$ (Fig. 3B), and post hoc analysis showed that mice injected with the mimetic peptide obtained a memory index score better than the two control groups (Ps<0.05).

These results suggested that control mice were not able to recover the memory of the exact position of the platform $1 \mathrm{mo}$ after the learning sessions. In contrast, mice with an injection of the PSA mimetic peptide searched for the platform in the exact position.

\section{Effect of PSA mimetic peptide infusion on the spatial index, swimming speed, and thigmotactism}

To study the patterns of change in the spatial index score over time, we pooled all the data concerning this index (Fig. 4). A one-factor ANOVA revealed a significant decrease of this index with the augmentation of the retention interval for all the groups (PBS: $F_{(2,26)}=8.045, P=0.002$; reverse: $F_{(2,27)}=5.055, P=0.014$; pr2: $\left.F_{(2,25)}=9.566, P=0.001\right)$. Nevertheless, mice injected with the PSA mimetic peptide showed stabilized performances in the probe test between the first and the fourth weeks.

Finally, we also checked that there were no differences in swimming speed and time spent in periphery in the 60 -sec probe test trial whether it was performed $24 \mathrm{~h}, 1 \mathrm{wk}$, or $4 \mathrm{wk}$ after training (Table 1$)\left(24 \mathrm{~h}: F_{(1,25)}=0.875, P=0.359 ; 1\right.$ wk: $F_{(1,34)}=2.157, P=0.151 ; 4$ wk: $\left.F_{(1,22)}=0.186, P=0.670\right)$. The one-factor ANOVA on time spent in periphery zone showed no treatment effect at $24 \mathrm{~h}\left(F_{(1,25)}=0.641, P=0.431\right)$, at $1 \mathrm{wk}$ $\left(F_{(1,34)}=0.013, P=0.908\right)$, and at $4 \mathrm{wk}\left(F_{(1,22)}=2.126, P=0.159\right)$. These results suggest that the pr2 injection induced an increase in memory performance revealed by the probe test since the performances measured are not the result of an increase in swimming speed or a strategy change.

\section{Discussion}

In this study, by using a bioactive peptide mimicking known functions of the carbohydrate PSA on NCAM, we investigated the role of the PSA-NCAM isoforms located within the dorsal hippocampal CA3 region in the elaboration of the long-term memory process. We clearly show that injection of PSA synthetic mimetic

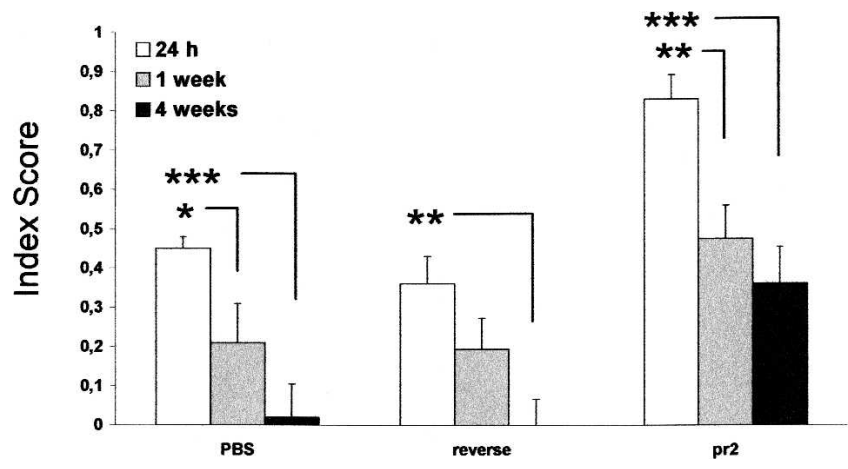

Figure 4. Spatial index for the different retention intervals. Histograms illustrate the spatial index score calculated as the difference between the number of annulus crossings surrounding the expected position of the platform and the mean number of crossings of the three remaining annuli, divided by the total number of annulus crossings, during probe trials. This index score is presented for PBS, reverse, and pr2 groups. ${ }^{* * *} P<0.001,{ }^{* *} P<0.01,{ }^{*} P<0.05$. peptide enhances the retrieval performance for up to $4 \mathrm{wk}$ posttraining.

In our experiments, we used a learning massed procedure of the MWM and focal injection of the peptide $5 \mathrm{~h}$ after the last training session, at the time point corresponding to the second wave of glycoprotein synthesis. Procedures with rapid acquisition, such as the passive-avoidance task or fear conditioning, are best suited for the study of memory consolidation. Post-training events are easier to study when the acquisition phase is performed over a short period of time. The new behavioral procedure with massed sessions we used, with all training performed in one session not exceeding $80 \mathrm{~min}$, is the closest to the single trial task. With the procedure we used, evaluation of learning performed soon after the training session is, however, less precise than with the passive avoidance task or fear conditioning procedures. Nevertheless, the short intersession interval allowed us to study the first memory consolidation phases of spatial information and, in particular, to perform peptide injection during the second wave of protein synthesis. In our experiments, the two control mouse groups present a very good performance level on the recall probe test performed $24 \mathrm{~h}$ after training, as already shown (Sargolini et al. 2003; Florian and Roullet 2004). One week-tested mice actively searched for the platform location in the correct quadrant with a performance similar to that shown during the 24 -h probe test. By contrast, when the probe test was performed $4 \mathrm{wk}$ later, the control animals were not able to search for the exact platform location, although they spent more time in the quadrant where the platform was located during the acquisition phase.

Injection of pr2 peptide directly into the CA3 region $5 \mathrm{~h}$ after the training phase improved 24 -h post-training retrieval performance in comparison with control groups. Pr2-injected mice present a recall performance level never reached with our behavioral procedure, although control mice already present a good performance level during this recall test. On average, pr2treated mice spent $80 \%$ of time searching for the platform in the correct quadrant and crossed the target sector seven times more than the three others. This increase in the performance level could be explained in two ways: It reflects either an increase of memory capacity or impairment of behavioral flexibility. It is indeed possible that during the probe test in the absence of the platform, the control mice first actively searched for the platform in the correct spatial location and then extended their search to the whole pool. In contrast, pr2-injected mice would persist in the fruitless search within the target sector instead of widening their explorative activity. However, we observed the same improvement in performance in mice injected with pr2 if the analysis was performed in the first $30 \mathrm{sec}$ of the probe trial (data not shown). This observation strongly suggests that the enhancement in performance is not due to a lack of flexibility but to the fact that the pr2 peptide has a direct effect on the cognitive abilities. To seek further support for this interpretation, we tested the retrieval performance level of mice after longer retention intervals. In probe tests performed 1 wk after training, pr2-injected mice presented a better retrieval performance level than do the control groups. Strikingly, when the tests were performed 4 wk after training, only mice injected with the pr2 peptide searched with precision for the correct platform location. One month after acquisition, the performance level stayed high and equalled the mean level of control mice tested $24 \mathrm{~h}$ post-training. Hence, in these experiments, PSA mimetic peptide injection enhanced significantly the memory retention of mice. This confirms the role of CA3 region on the long-term memory formation and demonstrates the specific involvement of PSA-NCAM in this event.

Reciprocally, and in line with this contention, it was already known that the blocking of PSA-NCAM expression causes a spa- 
Table 1. Average ( \pm SEM) of velocity swimming and periphery time $(13 \mathrm{~cm}$ from wall) during the $60-\mathrm{sec}$ probe test trial $24 \mathrm{~h}, 1 \mathrm{wk}$, and 4 wk after training

\begin{tabular}{|c|c|c|c|c|c|c|}
\hline & \multicolumn{2}{|c|}{$24 \mathrm{~h}$} & \multicolumn{2}{|c|}{$1 \mathrm{wk}$} & \multicolumn{2}{|c|}{$4 \mathrm{wk}$} \\
\hline & Speed $(\mathrm{cm} / \mathrm{sec})$ & Periphery (sec) & Speed $(\mathrm{cm} / \mathrm{sec})$ & Periphery (sec) & Speed $(\mathrm{cm} / \mathrm{sec})$ & Periphery (sec) \\
\hline $\begin{array}{l}\text { Control } \\
\text { pr2 peptide }\end{array}$ & $\begin{array}{l}17.96 \pm 0.90 \\
16.25 \pm 1.87\end{array}$ & $\begin{array}{c}13.79 \pm 1.42 \\
15.7 \pm 1.36\end{array}$ & $\begin{array}{l}18.20 \pm 0.94 \\
20.24 \pm 0.50\end{array}$ & $\begin{array}{l}18.27 \pm 1.71 \\
18.57 \pm 2.55\end{array}$ & $\begin{array}{l}20.16 \pm 0.64 \\
19.67 \pm 0.96\end{array}$ & $\begin{array}{l}19.95 \pm 2.72 \\
13.73 \pm 2.53\end{array}$ \\
\hline
\end{tabular}

Data represent the average of the swimming speed $(\mathrm{cm} / \mathrm{sec} \pm \mathrm{SEM})$ and the average of time (second \pm SEM) spent in the periphery area of the Morris pool (13-cm-wide wall zone) during the 60 -sec probe test trial conducted $24 \mathrm{~h}, 1 \mathrm{wk}$, or 4 wk after training. Control (PBS, reverse) and pr2 peptide refer to $5 \mathrm{~h}$ post-training bilateral intrahippocampal CA3 region infusions.

tial memory deficit in the Morris task, suggesting that these molecules play a crucial role in memory processes (Becker et al. 1996). Recently, an increase in polysialylated forms of NCAMs in the dentate gyrus has been observed $10-12 \mathrm{~h}$ after training in the spatial water maze (Sandi et al. 2003). In addition, during this behavioral task with massed learning sessions, an increase in polysialylation level has been correlated with a low learning behavioral performance level (Sandi et al. 2004). Here, by a gainof-function experiment, we confirmed that the PSA portion of the NCAM is a key player in long-term memory.

Two studies involving the use of peptides mimicking distinct portions of NCAM protein backbone and probably interfering with different NCAM functions have been published (Cambon et al. 2003, 2004). First, intracerebroventricular injections of C3d, a peptide that binds to the IgI module of NCAM and triggers the neurotogenic response in vitro and disrupting NCAMmediated cell adhesion (Kiryushko et al. 2003), induced an impairment of memory consolidation for passive avoidance learning (Foley et al. 2000) and contextual fear conditioning (Cambon et al. 2003). In contrast, a similar delivery route for a synthetic 15 -amino-acid peptide corresponding to the binding site of NCAM for the fibroblast growth factor receptor 1 (FGFR1), caused the opposite effect in the same paradigms and in the MWM (Cambon et al. 2004). As in cultured neurons, this peptide enhanced synaptogenesis; the investigators proposed that the improvement in the performance level was due to the increase in synaptic efficiency. It should also be kept in mind that PSA exhibits functions distinct from its proteic NCAM backbone, as recently confirmed by an elegant genetic approach (Weinhold et al. 2005).

A view now supported by several observations in literature is that a reduction in the concentration of adhesion molecules by internalization in invertebrates or by the expression of PSANCAM in vertebrates relieves constraint on the structural remodeling that takes place during learning and memory. In this context, it is likely that the PSA mimicking peptide potentializes the effect of PSA-NCAM in these events. Further experiments will be necessary to achieve a precise mechanistic understanding of the interactions, but a likely mechanism is that pr2 increases the magnitude of the repulsive pressure exerted between membranes, which is a function of the PSA density (Johnson et al. 2005).

In our study, we chose to inject the mimetic peptide pr2 directly into the CA3 region because this hippocampal field is involved in spatial memory consolidation (Florian and Roullet 2004). In addition, our preliminary data (data not shown) showing that blocking CREB transcription factor or protein synthesis in the CA3 region caused a strong spatial long-term memory deficit further support this view. The early phase of memory consolidation is often associated with structural remodeling in both the dendritic and axonal synaptic field in the hippocampus (Murphy and Regan 1998), particularly in the CA3 region (Stewart et al. 2005). Moreover, in numerous computational studies, the CA3 region is assumed to operate as an auto-associative net- work during the storage and retrieval of the information (Treves and Rolls 1992; Rolls and Treves 1998). During acquisition phase, each input reaching this subregion will be stored as a pattern of activity that requires a reorganization of pre-existing synapses or new synapse formation. PSA-NCAMs probably play a role in this synaptic reorganization, and pr2 might potentialize its effect, thus improving memory consolidation of information that has an impact on the long-term retrieval quality. A second nonexclusive hypothesis is that pr2 peptide also acts on the connections between the CA3 neurons and the axons of the newly formed dentate gyrus granular cells. This hippocampus subfield presents extensive neo-neurogenesis in the adult (Kempermann et al. 1997; Cameron and McKay 2001), which could be increased after a spatial training procedure (Gould et al. 1999). Moreover, in the dentate gyrus, the newly generated cells present strong polysialylation of NCAM (Seki and Arai 1993, 1995). Pr2 peptide possibly supports the axonal growth or the synaptogenesis of these new neurons that project into area CA3, helping their contact with pyramidal cells.

Already at this stage, our study can provide additional information regarding the molecular and cellular mechanisms of memory consolidation and points to the potential beneficial effects of strategies aimed at promoting specific aspects of PSANCAM functions in cognitive tasks. The therapeutic efficacy of these small PSA-mimicking peptides on memory-related disorders remains to be tested in appropriate animal models.

\section{Materials and Methods}

\section{Animals}

Male and female C57BL/6 inbred mice born in our laboratory have been used. After birth, they remained with their two parents until weaning at $21 \mathrm{~d}$ of age. Then they were placed in groups of three to six animals of the same sex and same age, in standard breeding cages placed in a rearing room at a constant temperature $\left(23 \pm 1^{\circ} \mathrm{C}\right)$ under diurnal conditions (light-dark, 8:00 a.m.8:00 p.m.), with food and water ad libitum. At the time of surgery, they were $100 \mathrm{~d}$ old $( \pm 10 \mathrm{~d})$. They were tested during the second half of the light period (between 1:30 p.m. and 5:00 p.m.).

Every possible effort was made to minimize animal suffering, and all procedures were in strict accordance with European community and French national laws and regulations on the use of animals in research and National Institutes of Health (NIH) guidelines on animal care.

\section{Surgery}

Mice were anesthetized with chloral hydrate $(400 \mathrm{mg} / \mathrm{kg})$ and placed in a stereotaxic apparatus (David Kopf Instruments) with mouse adapter and lateral bars. The head skin was cut longitudinally, and bilateral guide cannulae $(0.56 \mathrm{~mm}$ in diameter) were implanted bilaterally $1.2 \mathrm{~mm}$ above the CA3 region. The following coordinates with lambda and bregma in the same horizontal plane were used: posterior to bregma, $-1.6 \mathrm{~mm}$; lateral to midline, $\pm 2.5 \mathrm{~mm}$ and $1.5 \mathrm{~mm}$ beneath the skull surface, according to Franklin and Paxinos (1997). The subjects were then left in their home cage for a recovery period of $7-8 \mathrm{~d}$. 


\section{Peptide synthesis}

Mimotope peptide pr2, CSLIASMETGCG (MW 1168), with a disulfide bridge linking cysteine 1 and 11, was selected by biopanning of a phage library displaying constrained random nonamer cyclic peptides with an anti-PSA antibody. pr2 was synthesized by using Fmoc chemistry in a solid-phase synthesizer, purified by HPLC, and its sequence and structure were confirmed by mass spectrometry. The ability of the peptide to mimic PSA biological functions was tested in in vitro and in vivo tests as described (Torregrossa et al. 2004). The reverse peptide, GCGTEMSAILSC (MW 1169), with a disulfide bridge linking cysteine 2 and 12, was used as control; all used peptides were $>95 \%$ pure.

\section{Intracranial injection procedure}

PSA mimetic peptide pr2 and the control reverse peptide were dissolved $(0.01 \mathrm{M})$ with PBS $(1 \times)$ and were bilaterally injected in a volume of $0.25 \mu \mathrm{L} /$ side into the dorsal hippocampus. The stylus was removed from the guide cannulae, and an injection needle ( $0.25 \mathrm{~mm}$ in diameter) was inserted into the guide cannulae. The injector was connected with a polyethylene tubing to a $1-\mu \mathrm{L}$ Hamilton syringe driven by a microinjection pump at a rate of $0.1 \mu \mathrm{L} / \mathrm{min}$. Mice were maintained in their cages during the injection time. The injection time was 2 min 30 sec for each side, and the needle was left in place for an additional $60 \mathrm{sec}$ to allow diffusion.

\section{Spatial learning in the MWM}

The water maze was an ivory circular pool $(110 \mathrm{~cm}$ diameter, 30 $\mathrm{cm}$ high) filled to a depth of $15 \mathrm{~cm}$ with water maintained at $23 \pm 1^{\circ} \mathrm{C}$. The water was made opaque by addition of a white opacifier. A white-painted platform (9 $\mathrm{cm}$ diameter) was placed inside the pool, $15.5 \mathrm{~cm}$ away from the pool wall. The apparatus was placed in an experimental room, and several extramaze visual cues, $\sim 50-100 \mathrm{~cm}$ away from the pool, were attached to the walls. Four start positions were located around the perimeter of the pool, dividing its surface into four equal quadrants. The swimming pool was surmounted by a video camera connected to a video recorder and a computerized tracking system (Ethovision, Noldus).

Massed-procedure in the spatial MWM has been used as described previously (Sargolini et al. 2003; Florian and Roullet 2004). Briefly, 1 wk after surgery, mice were placed in the experimental room, and 15 min later, mice were individually subjected to a single familiarization session of three trials with the platform located always in the same quadrant and protruding $0.5 \mathrm{~cm}$ over the surface of the water. The session started with the mouse standing on the platform for $60 \mathrm{sec}$. At the beginning of each trial, mice were introduced into the maze facing the wall at one of the different starting points and allowed to swim freely until they reached the platform. Mice failing to find the platform within a fixed period of $60 \mathrm{sec}$ were gently guided by hand to the platform, and a maximum escape latency of $60 \mathrm{sec}$ was recorded. After the animals climbed onto the platform, they were allowed to remain on it for an additional $60 \mathrm{sec}$ and were subsequently replaced in the maze from a different starting position. The starting positions were determined in a pseudorandom order, such that each of them was used once in a single session.

At training, mice were given four consecutive sessions of three trials with an intersession interval of 15-20 min, during which they were returned to their home cage. The procedure was the same as in the familiarization phase except for the platform, which was submerged $0.5 \mathrm{~cm}$ beneath the surface of the water. Mice were required to navigate to the invisible platform by using the spatial cues available in the room.

Five hours after the last training trial, mice received a bilateral $0.25-\mu \mathrm{L}$ injection with pr2, reverse, or PBS solution. Twentyfour hours or 1 or $4 \mathrm{wk}$ after training, mice were subjected to a single probe test trial. The platform was removed, and mice, starting from the center of the pool, were allowed a 60 -sec search for the platform. During the probe test, two main measures were scored: (1) the time spent in each quadrant of the pool and (2) the number of annulus crossings, the number of times a mouse crossed an ideal circle (14-cm diameter) located around each of the four possible platform positions in the four quadrants. These two behavioral variables measure spatial memory, but the number of annulus crossings reveals a more precise search for the platform than the time spent in the quadrants. In other words, with the time variable it is possible to know whether mice are able to approximately locate the platform and, with the annulus crossings variable, whether mice search at the exact position of the platform. We use the latter basic measures to calculate an index score, as the difference between the number of crossings of the annulus surrounding the expected position of the platform (target, T) and the mean number of crossings of the three remaining annuli (opposite, $\mathrm{O}$; adjacent 1, A1; adjacent 2, A2), divided by the total number of annulus crossings according to the following formula: index score $=(\mathrm{T}-(\mathrm{O}+\mathrm{A} 1+\mathrm{A} 2) / 3) /$ $\mathrm{T}+\mathrm{O}+\mathrm{A} 1+\mathrm{A} 2)$. In addition, the movements of the animals during the probe test were recorded by using the computerized detection system. The position of the animal was determined five times per second and recorded as $X$ and $Y$ coordinates in time. Subsequently, these data have been employed to calculate the average swimming speed and the time spent in the periphery area (situated $13 \mathrm{~cm}$ from the wall).

\section{Cannulae placement verification}

On completion of the experiment, mice were sacrificed, and brains were removed and frozen at $-20^{\circ} \mathrm{C}$. Cannulae placements were determined by examination of serial coronal sections (40 $\mu \mathrm{m})$ stained with thionine. Serial sections were subjected to binocular microscopic inspection with high magnification $(40 \times)$ to exclude cell layers in CA1 or CA4 regions formed mainly by infiltration of glial cells. Mice that presented injections that had overflowed into the CA1 or CA4 regions were removed from the statistical analysis.

\section{Statistical analysis}

The SYSTAT 9.0 statistical software package was used for data analysis. The results were expressed as mean \pm SEM and analyzed by using one-way ANOVA or a repeated-measure ANOVA as appropriate. Post hoc multiple comparisons were carried out when possible, using Tukey's "Honestly Significantly Different" (HSD) test. Significance of results was accepted at $P<0.05$.

\section{Acknowledgments}

Work supported by institutional grants from CNRS, and financial support from IRME and AFM to G.R.

\section{References}

Alexinsky, T., Przbyslawski, J., Mileusnic, R., Rose, S.P.R., and Sara, S.J. 1997. Antibody to day-old chick brain glycoprotein produces amnesia in adult rats. Neurobiol. Learn. Mem. 67: 14-20.

Ambrogi Lorenzini, C.G., Baldi, E., Bucherelli, C., Sacchetti, B., and Tassoni, G. 1999. Neural topography and chronology of memory consolidation: A review of functional inactivation findings. Neurobiol. Learn. Mem. 71: 1-18.

Andersen, P. and Soleng, A.F. 1998. Long-term potentiation and spatial training are both associated with the generation of new excitatory synapses. Brain Res. Brain Res. Rev. 26: 353-359.

Arami, S., Jucker, M., Schachner, M., and Welzl, H. 1996. The effect of continuous intraventricular infusion of L1 and NCAM antibodies on spatial learning in rats. Behav. Brain Res. 81: 81-87.

Bailey, C.H., Chen, M., Keller, F., and Kandel, E.R. 1992. Serotonin-mediated endocytosis of apCAM step of learning-related synaptic growth in Aplysia. Science 256: 645-649.

Bailey, C.H., Giustetto, M., Huang, Y.Y., Hawkins, R.D., and Kandel, E.R. 2000. Is heterosynaptic modulation essential for stabilizing Hebbian plasticity and memory? Nat. Rev. Neurosci. 1: 11-20.

Becker, C.G., Artola, A., Gerardy-Schahn, R., Becker, T., Welzl, H., and Schachner, M. 1996. The polysialic acid modification of the neural cell adhesion molecule is involved in spatial learning and hippocampal long-term potentiation. J. Neurosci. Res. 45: 143-152.

Cambon, K., Venero, C., Berezin, V., Bock, E., and Sandi, C. 2003. Post-training administration of a synthetic peptide ligand of the neural cell adhesion molecule, C3d, attenuates long-term expression of contextual fear conditioning. Neuroscience 122: 183-191.

Cambon, K., Hansen, S.M., Venero, C., Herrero, A., Skibo, G., Berezin, V., Bock, E., and Sandi, C. 2004. A synthetic neural cell adhesion 
molecule mimetic peptide promotes synaptogenesis, enhances presynaptic function, and facilitates memory consolidation. $J$. Neurosci. 24: 4197-4204.

Cameron, H.A. and McKay, R.D. 2001. Adult neurogenesis produces a large pool of new granulate cells in the dentate gyrus. J. Comp. Neurol. 435: 406-417.

Cremer, H., Lange, R., Christoph, A., Plomann, M., Vopper, G., Roes, J., Brown, R., Baldwin, S., Kraemer, P., Scheff, S., et al. 1994. Inactivation of the N-CAM gene in mice results in size reduction of the olfactory bulb and deficits in spatial learning. Nature 367: 455-459.

Doyle, E., Bell, R., and Regan, C.M. 1992a. Hippocampal NCAM 180 transiently increases sialylation during the acquisition and consolidation of a passive avoidance response in the adult rat. $J$. Neurosci. Res. 31: 33-49.

Doyle, E., Nolan, P.M., Bell, R., and Regan, C.M. 1992b. Intraventricular infusions of anti-neural cell adhesion molecules in a discrete post-training period impair consolidation of a passive avoidance response in the rat. J. Neurochem. 59: 1750-1753.

Dudai, Y. 2004. The neurobiology of consolidation, or how stable is the engram? Annu. Rev. Psychol. 55: 51-86.

Dudai, Y. and Morris, R.G.M. 2000. To consolidate or not to consolidate: What are the questions? In Brain, perception, memory: Advances in cognitive sciences. (ed. J.J. Bulhuis), pp. 149-162. Oxford University Press, Oxford, UK.

Eckhardt, M., Bukalo, O., Chazal, G., Wang, L., Goridis, C., Schachner, M., Gerardy-Schahn, R., Cremer, H., and Dityatev, A. 2000. Mice deficient in the polysialyltransferase ST8SiaIV/PST-1 allow discrimination of the roles of neural cell adhesion molecule protein and polysialic acid in neural development and synaptic plasticity. $J$. Neurosci. 15: 5234-5244.

Florian, C. and Roullet, P. 2004. Hippocampal CA3-region is crucial for acquisition and memory consolidation in Morris water maze tasks in mice. Behav. Brain Res. 154: 365-374.

Foley, A.G., Hartz, B.P., Gallagher, H.C., Rønn, L.C., Berezin, V., Bock, E., and Regan, C.M. 2000. A synthetic peptide ligand of neural cell adhesion molecule (NCAM) IgI domain prevents NCAM internalization and disrupts passive avoidance learning. $J$. Neurochem. 74: 2607-2613.

Fox, G.B., O'Connell, A.W., Murphy, K.J., and Regan, C.M. 1995. Memory consolidation induces a transient and time-dependent increase in the frequency of neural cell adhesion molecule polysialylated cells in the adult rat hippocampus. J. Neurochem. 65: 2796-2799.

Franklin, K.B.J. and Paxinos, G. 1997. The mouse brain in stereotaxic coordinates. Academic Press, San Diego.

Gould, E., Beylin, A., Tanapat, P., Reeves, A., and Shors, T.J. 1999 Learning enhances adult neurogenesis in the hippocampal formation. Nat. Neurosci. 2: 260-265.

Johnson, C.P., Fujimoto, I., Rutishauser, U., and Leckband, D.E. 2005. Direct evidence that neural cell adhesion molecule (NCAM) polysialylation increases intermembrane repulsion and abrogates adhesion. I. Biol. Chem. 280: 137-145.

Kempermann, G., Kuhn, H.G., and Gage, F.H. 1997. More hippocampal neurons in adult mice living an enriched environment. Nature 386: 493-495.

Kiryushko, D., Kofoed, T., Skladchikova, G., Holm, A., Berezin, V., and Bock, E. 2003. A synthetic peptide ligand of NCAM, C3d, promotes neuritogenesis and synaptogenesis and modulates presynaptic function in primary cultures of rat hippocampal neurons. J. Biol. Chem. 278: 12325-12334.

Martin, S.J., Grimwood, P.D., and Morris, R.G.M. 2000. Synaptic plasticity and memory: An evaluation of the hypothesis. Annu. Rev. Neurosci. 23: 649-711.

McGaugh, J.L. 2000. Memory: A century of consolidation. Science 287: 248-251.

Muller, G.E. and Pilzecker, A. 1900. Experimentelle Beitrage zur Lehre von Gedächtnis. Z. Psychol. 1: 1-300.

Muller, D., Wang, C., Skibo, G., Toni, N., Cremer, H., Calaora, V., Rougon, G., and Kiss, J.Z. 1996. PSA-NCAM is required for activity-induced synaptic plasticity. Neuron 17: 413-422.

Murphy, K.J. and Regan, C.M. 1998. Contributions of cell adhesion molecules to altered synaptic weights during memory consolidation.
Neurobiol. Learn. Mem. 70: 73-81.

O'Connell, A.W., Fox, G.B., Barry, T., Murphy, K.J., Fichera, G., Foley, A.G., Kelly, J., and Regan, C.M. 1997. Spatial learning activates neural cell adhesion molecule polysialylation in a corticohippocampal pathway within the medial temporal lobe. J. Neurochem. 6: 2538-2546.

Rolls, E.T. and Treves, A. 1998. Neural networks and brain function. Oxford University Press, Oxford, UK.

Ronn, L.C.B., Bock, E., Linnemann, D., and Jahnsen, H. 1995. NCAM-antibodies modulate induction of long-term potentiation in rat hippocampal CA1. Brain Res. 677: 145-151.

Rose, S.P.R. 1995a. Cell adhesion molecules, glucocorticoids and long term memory formation. Trends Neurosci. 18: 502-506.

- 1995b. Glycoproteins and memory formation. Behav. Brain Res. 66: 73-78.

Rougon, G. 1993. Structure, metabolism and cell biology of polysialic acids. Eur. J. Cell Biol. 61: 197-207.

Roullet, P., Mileusnic, R., Rose, S.P.R., and Sara, S.J. 1997. Neural cell adhesion molecules play a role in rat memory formation in appetitive as well as aversive tasks. Neuroreport 8: 1907-1911.

Sandi, C., Merino, J.J., Cordero, M.I., Kruyt, N., Murphy, K.J., and Regan, C.M. 2003. Differential modulation of hippocampal NCAM polysialylation by stressful and traumatic experiences suggests distinct memory encoding mechanisms. Biol. Psychology 54: $599-607$.

Sandi, C., Cordero, M.I., Merino, J.J., Kruyt, N.D., Regan, C.M., and Murphy, K.J. 2004. Neurobiological and endocrine correlates of individual differences in spatial learning ability. Learn. Mem. 11: $244-252$.

Sargolini, F., Florian, C., Oliverio, A., Mele, A., and Roullet, P. 2003. Differential involvement of NMDA and AMPA receptors within the nucleus accumbens in consolidation of information necessary for place navigation and guidance strategy, in mice. Learn. Mem. 10: $285-293$.

Scholey, A.B., Rose, S.P.R., Zamani, M.R., Bock, M.R., and Schachner, M. 1993. A role for the neural cell adhesion molecule in a late, consolidating phase of glycoprotein synthesis six hours following passive avoidance training in the young chick. Neuroscience 55: $499-509$.

Seki, T. and Arai, Y. 1993. Highly polysialylated neural cell adhesion molecule (NCAM-H) is expressed by newly generated granule cells in the dentate gyrus of the adult rat. J. Neurosci. 13: 2351-2358.

- 1995. Age-related production of new granule cells in the adult dentate gyrus. Neuroreport 6: 2479-2482.

Stewart, M.G., Davies, H.A., Sandi, C., Kraev, I.V., Rogachevsky, V.V., Peddie, C.J., Rodriguez, J.J., Cordero, M.I., Donohue, H.S., Gabbott P.L.A., et al. 2005. Stress suppresses and learning induces plasticity in CA3 of rat hippocampus: A three-dimensional ultrastructural study of thorny excrescences and their postsynaptic densities. Neuroscience 131: 43-54.

Stupien, G., Florian, C., and Roullet, P. 2003. Involvement of the hippocampal CA3-region in acquisition and in memory consolidation of spatial but not in object information in mice. Neurobiol. Learn. Mem. 80: 32-41.

Torregrossa, P., Buhl, L., Bancilia, M., Durbec, P., Schafer, C., Schachner, M., and Rougon, G. 2004. Selection of poly- $\alpha 2,8$-sialic acid mimotopes from a random phage peptide library and anlysis of their bioactivity. J. Biol. Chem. 279: 30707-30714.

Treves, A. and Rolls, E.T. 1992. Computational constraints suggest the need for two distinct input systems to the hippocampal CA3 network. Hippocampus 2: 189-200.

Tiunova, A., Anokhin, K.V., Schachner, M., and Rose, S.P.R. 1998. Three time windows for amnestic effect of antibodies to cell adhesion molecule L1 in chicks. Neuroreport. 9: 1645-1648.

Weinhold, B., Seidenfaden, R., Roeckle, I., Mühlenhoff, M., Schertzinger, F., Conzelmann, S., Marth, J.D., Gerardy-Schahn, R., and Hildebrandt, H. 2005. Genetic ablation of polysialic acid causes severe neurodevelopmental defects rescued by deletion of the neural cell adhesion molecule. J. Biol. Chem. 280: 42971-42977.

Received September 29, 2005; accepted in revised form February 7, 2006. 


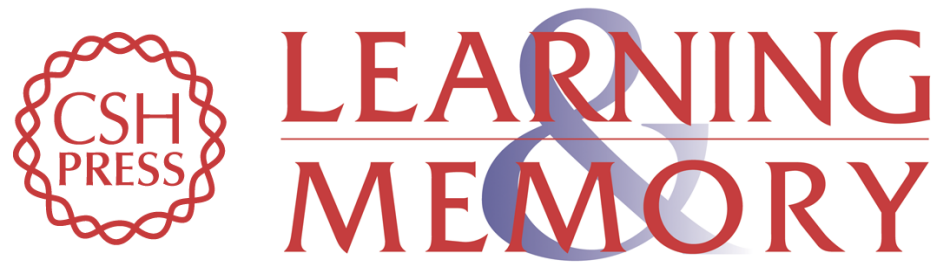

Post-training intrahippocampal injection of synthetic poly- $\alpha$ -2,8-sialic acid-neural cell adhesion molecule mimetic peptide improves spatial long-term performance in mice

Cédrick Florian, Jane Foltz, Jean-Chrétien Norreel, et al.

Learn. Mem. 2006, 13:

Access the most recent version at doi:10.1101//m.187506

References This article cites 45 articles, 10 of which can be accessed free at: http://learnmem.cshlp.org/content/13/3/335.full.html\#ref-list-1

License

Email Alerting Receive free email alerts when new articles cite this article - sign up in the box at the Service top right corner of the article or click here. 